\title{
THE RELATIONSHIP BETWEEN THE MORPHOLOGICAL AND STRUCTURAL CHANGES OF POPULUS EUPHRATICA OLIV. AND ENDOGENOUS HORMONE CONTENTS
}

\author{
HAN, X. L. ${ }^{1,2,3}-$ ZHAI, J. T. ${ }^{1,2,3}-$ GAI, Z. S. ${ }^{1,2,3}-$ LI, Z. J. ${ }^{1,2,3 *}$ \\ ${ }^{1}$ Key Laboratory of Protection and Utilization of Biological Resources in Tarim Basin Xinjiang \\ Production and Construction Corps, Alar, Xinjiang 843300, China \\ ${ }^{2}$ Desert Poplar Research Center of Tarim University, Alar, Xinjiang 843300, China \\ ${ }^{3}$ College of Life Science, Tarim University, Alar, Xinjiang 843300, China \\ *Corresponding author \\ e-mail: lizhijun0202@126.com; phone: +86-997-468-1202
}

(Received $11^{\text {th }}$ Dec 2020; accepted $18^{\text {th }}$ Mar 2021)

\begin{abstract}
Populus euphratica Oliv. exhibits heterophylly, which is regarded as a manifestation of evolutionary adaptation to extremely arid environments. To clarify the relationship between Morphological and structure changes of P. euphratica (Populus euphratica Oliv) and its physiological characteristics, we studied the changes in the morphological structures, carbohydrates, endogenous hormone levels and their ratios, as well as their relationships during the developmental stages, and heterophylly at crown height. Correlation analysis shows, IAA and $\mathrm{GA}^{3}$ contents, as well as the ratios of IAA/ABA, $\mathrm{GA}_{3} / \mathrm{ABA}$ and $\mathrm{ZR} / \mathrm{ABA}$, were negatively correlated with $\mathrm{LW}$ and LA and were positively correlated with LL and LI. IAA, ZR, IAA/ABA, and ZR/ABA were negatively correlated with LT. $\mathrm{GA}_{3}$, $\mathrm{IAA}, \mathrm{GA}_{3} / \mathrm{ABA}$, and IAA/ABA were significantly or extremely significantly correlated with $\mathrm{ECN}$, PTCL, PTT and PSR. The content of soluble sugar, starch and soluble protein were positively correlated with the LI and negatively correlated with LA, PL, LW, ECN and PTC. P. euphratica regulates the drought resistance at different developmental stages by changing the content and ratio of 4 hormones in heterogeneous leaves and the synergistic changes of some anatomical structures, and adapts to arid environment.
\end{abstract}

Keywords: ecological adaptation strategy, heterophylly, morphological anatomy, physiological characteristics

\section{Introduction}

Plants are constantly subjected to various environmental stresses throughout their whole life cycle, especially in desert ecosystems, and plant responses to adverse conditions may be complex combinations of physiological, morphological, and longterm adaptation strategies. Air contact generally do not affect plants leaves negatively but its extremes such as very high temperature or very low air humidity could lead to stresses, Leaves are extremely sensitive to environmental changes during species evolution and individual growth and development, showing strong plasticity (Yang et al., 2019a). Leaf traits directly affect the basic behaviour and functions of plants, have the closest relationship with plant biomass and plant resource acquisition, utilization and utilization efficiency, and can reflect the survival strategies formed by plants adapting to environmental changes (Huang et al., 2010a). For example, the leaves in young plants of Sabina chinensis are needle-shaped, while the old ones are scales. This phenomenon of having leaves of different shapes on the same plant is called heterophylly. Heterophylly is a genetic mechanism that accumulates during the long- 
term adaptation process of plants to the environment (Zhang et al., 2017) and the leaf structure also best reflects the adaptability characteristics of plants in adversity (Cao, 2005; Xu, 2018). P. euphratica has biological characteristics of heterophylly, which are successively manifested in the appearance of strip, lanceolate, ovate, and broad-ovate leaves at different developmental stages from seedling and sapling to adult trees (Plate 1 in the Appendix). Studies have confirmed that there is a significant negative correlation between the age of $P$. euphratica and the leaf index (LI) and a positive correlation between age and leaf area (LA) (Huang et al., 2010a, b).

More recent studies have also revealed that plant hormones, including abscisic acid (ABA), gibberellin (GA), auxins (IAA) and zeatin-riboside (ZR), can affect heteromorphic leaf formation in many plant species. For example, analysis of the different developmental stages of Ludwigia arcuata showed that ABA played an important role in the changes in leaf morphology in underwater and above water conditions (Hokuto et al., 2017). The increased levels or responses of the plant hormone gibberellin (GA) in tomato leaves also led to the simplification of leaf shape (Yanai et al., 2011). Homologous members of the AUX/indole-3-acetic acid (IAA) gene family mediate the action of auxin in determining leaf shape by repressing the growth of regions with low auxin concentrations during simple and complex leaf development (Koenig et al., 2009). The growth and development of different types of leaves are also the result of the combined action of multiple hormones (Kalve et al., 2014; Morillon and Chrispeels, 2001). Previous studies showed that the hormone contents in leaves of $P$. euphratica also change with the age of the tree and morphological changes of heteromorphic leaves, however, it has not been reported how the changes in the hormone content and ratio of the heteromorphic leaves coordinate with the morphological structure to adapt to drought.

Leaf structure is sensitive and adaptable to the environment, and the change of leaf structure is an important mechanism for plants to adapt to environmental changes (He et al., 2018) For example, the leaves of plants grown in arid environments for a long time usually exhibit increased leaf thickness, thickened cuticle, increased thickness of palisade tissue, decreased or degraded sponge tissue thickness. (Li et al., 2016). Leaf morphology is formed by plants constantly adapting to changing environments in the process of evolution and selection, which can better reflect the adaptability of plants and affect the functions and performance of plants. (Yang et al., 2019b; Leigh et al., 2011), heteromorphic leaves that differ in their morphology exhibit various functional characteristics to adapt to environmental stress; thus, heteromorphic leaves may play a crucial role in plant adaptations to environmental changes. For example, the size of the leaves directly affects the degree to which plants receive light resources. Generally, larger leaves can enable plants to obtain more light energy. At the same time, leaf area affects leaf heat and water balance by affecting leaf temperature and transpiration rate (Wright et al., 2017). Several studies showed that from the base of the trunk to the top of the same individual of $P$. euphratica, the number of epidermal cells of heteromorphic leaves increased, the mesophyll cells were more closely arranged, the palisade tissues were increasingly developed, the sponge tissues were increasingly degenerate (Ding et al., 2010; Li et al., 2005), the xeric structure of broad-ovate leaves was more developed than that of lanceolate leaves, and stronger resistance was shown (Yang et al., 2005; Wang et al., 1997). During different developmental stages, there are gradual increases in the LA, leaf thickness (LT), number of leaf epithelial and hypodermal cells, epidermal cell length (ECL), and palisade tissue thickness (PTT) in P. euphratica from the base to the top of the crown, but there are gradual decreases in the leaf length (LL), LI, and sponge tissue 
thickness (STT) from the base to the top of the crown. Additionally, there is a significant correlation between morphological characteristics and anatomical structures (Zhao et al., 2016). Studies have shown that the contents of soluble sugar, starch and soluble protein in heteromorphic leaves are closely related to the morphological formation and ontogenetic stage of heteromorphic leaves ( $\mathrm{Li}$ et al., 2015). The levels and ratios of endogenous hormones of heteromorphic leaves of $P$. euphratica were significantly different at different canopies ( $\mathrm{Li}$ et al., 2017). However, studies on the changes in these morphological characteristics, anatomical structures, and carbohydrate and hormone levels, as well as their relationship during the development of heteromorphic leaves and how these ecological adaptation strategies are formed, are lacking.

$P$. euphratica was researched during different developmental stages in the same ecological environment. We studied the changes in the morphological characteristics, anatomical structure, carbohydrate, soluble protein and endogenous hormone levels and their ratio in different developmental stages and the vertical spatial distribution of the same individual crowns. The current study aims to clarify the relationship between various endogenous hormones, soluble sugars and the morphological and structural changes of $P$. euphratica heteromorphic leaves and establish a foundation to further reveal the regulatory mechanism of the morphological and structural changes of heteromorphic leaves at the molecular level.

\section{Materials and methods}

To minimize the environmental effects, we selected $P$. euphratica at different developmental stages but under the same site conditions. The conditions of the test site were introduced in previous studies (Zhai et al., 2019). The study site was located in the Populus euphratica forest ( $81^{\circ} 17^{\prime} 56.52^{\prime \prime}$ E, 40³2’36.90” N, $980 \mathrm{~m}$ above sea level) in the upper reaches of the Tarim River on the northwestern margin of the Tarim Basin, Xinjiang, China. This region has a hot, dry summer with little rainfall all year round. The average annual precipitation, potential evaporation and temperature are $50 \mathrm{~mm}$, $1900 \mathrm{~mm}$, and $10.8{ }^{\circ} \mathrm{C}$, respectively, with average annual sunshine of $2900 \mathrm{~h}$, representing a typical temperate desert climate (from the local meteorological bureau). The $P$. euphratica forest at the study site covered an area of 180.6 ha, with 355 individual $P$. euphratica trees.

\section{Experimental design and sampling}

Using the diameter at breast height $(\mathrm{DBH})$ and $2 \mathrm{~cm}$ as the interval, the forest was divided into nine diameter classes, indicating nine developmental stages of $P$. euphratica. Three sample trees with uniform crowns were selected from each diameter class, with 27 trees in total. During the leaf maturity period, the sampling canopy height was divided into 5 equal parts (total stations to measure the tree heights and under branch heights of trees in the different diameter classes from base to top was defined as 1 to 5 layers) (Table Al). At each sampling layer, twelve one-year-old branches were collected from the four directions of east, south, west and north. Sixty branches were collected from each sampling tree, and sample leaves were taken at the third node from the base of the branch. A total of 60 leaves per sampling were used to measure the leaf morphological, anatomical and physiological characteristics. The leaves used for the physiological characteristics were immediately stored in liquid nitrogen after collection. 


\section{Measurements of leaf morphological and anatomical parameters}

The leaf length (LL), leaf width (LW), leaf area (LA) and petiole length (PL) were measured using a scanner (CanoScan LiDE 700F, Canon) and LA-S plant image analysis software. The leaf index (LI) was calculated from the blade length/blade width ratio.

We used the paraffin section method to observe the leaf lamina anatomy. The blade was cut transversely at its widest part (Slicer:RM2135, Leica Instruments GmbH). The material that retained the primary vein and leaf margin was selected and fixed in a formalin-acetic acid-alcohol (FAA) solution. Tissue sections were prepared as 8 - $\mu \mathrm{m}$ thick paraffin sections, double-stained with sarranine-fast green, and mounted with neutral resin. The epidermal cell number (ECN), epidermal cell length (ECL), epidermal cell width (ECW), palisade tissue thickness (PTT), palisade tissue cell number (PTCN), palisade tissue cell length (PTCL), palisade tissue cell width (PTCW) and spongy tissue thickness (STT) were determined. The palisade tissue/sponge tissue ratio (PSR) was calculated. Five fields of view were observed for each leaf, and 20 values were obtained for each field of view (Digital stereo microscope, SMZ1500, Nikon). The average values for the leaf structural parameters in five fields of view were collected as the anatomical parameters of each leaf.

\section{Determination of carbohydrate and soluble protein contents}

The content of soluble sugar was determined by the anthrone-sulfuric acid method as described previously, starch content was determined by the anthrone-colorimetric method, and soluble protein content was determined by the Coomassie blue G-250 method (Juan et al., 2015; Song et al., 2017; Zhou et al., 2014).

\section{Determination of endogenous hormone content changes}

The stem tips of the same layer of branches in the sampled tree canopy were mixed as test samples. Test samples were accurately weighed to $200 \mathrm{mg}$, and the contents of indoleacetic acid (IAA), zeatinriboside (ZR), gibberellin ( $\left.\mathrm{GA}_{3}\right)$ and abscisic acid (ABA) were determined by enzyme-linked immunoassay as described previously (Duan et al., 2009; Li et al., 2019).

\section{Statistical analysis}

One-way ANOVA was used to compare the differences in the morphological, anatomical and physiological characteristics of the heteromorphic leaves. In SPSS 20.0, Duncan's new multiple range method was used for data analysis of variance, and the significance level was 0.05 .

\section{Results}

\section{Morphological characteristics of heteromorphic leaves change with development stage and tree height}

As shown in Figure 1, with the increase in diameter and crown level, the leaf length and leaf shape index showed a decreasing trend, while the leaf width, leaf thickness, petiole length and leaf area showed an increasing trend. The results showed that the morphology of the heteromorphic leaves varied with changes in diameter and canopy 
level. The heteromorphic leaves were distributed in the first to fifth layers of the crown of each diameter of $P$. euphratica, the leaf area was obviously larger, the leaves were thicker and the petioles became longer.
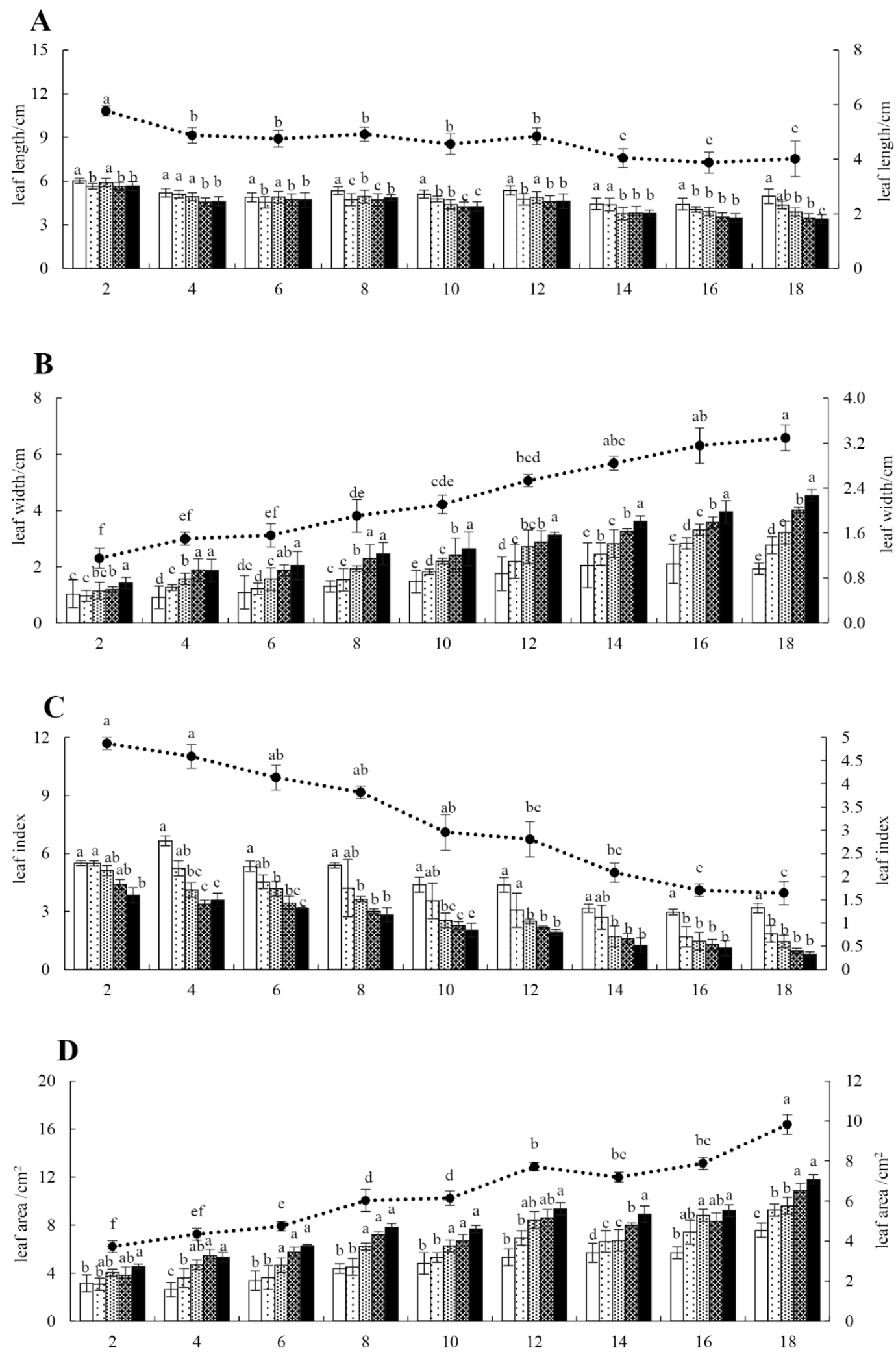

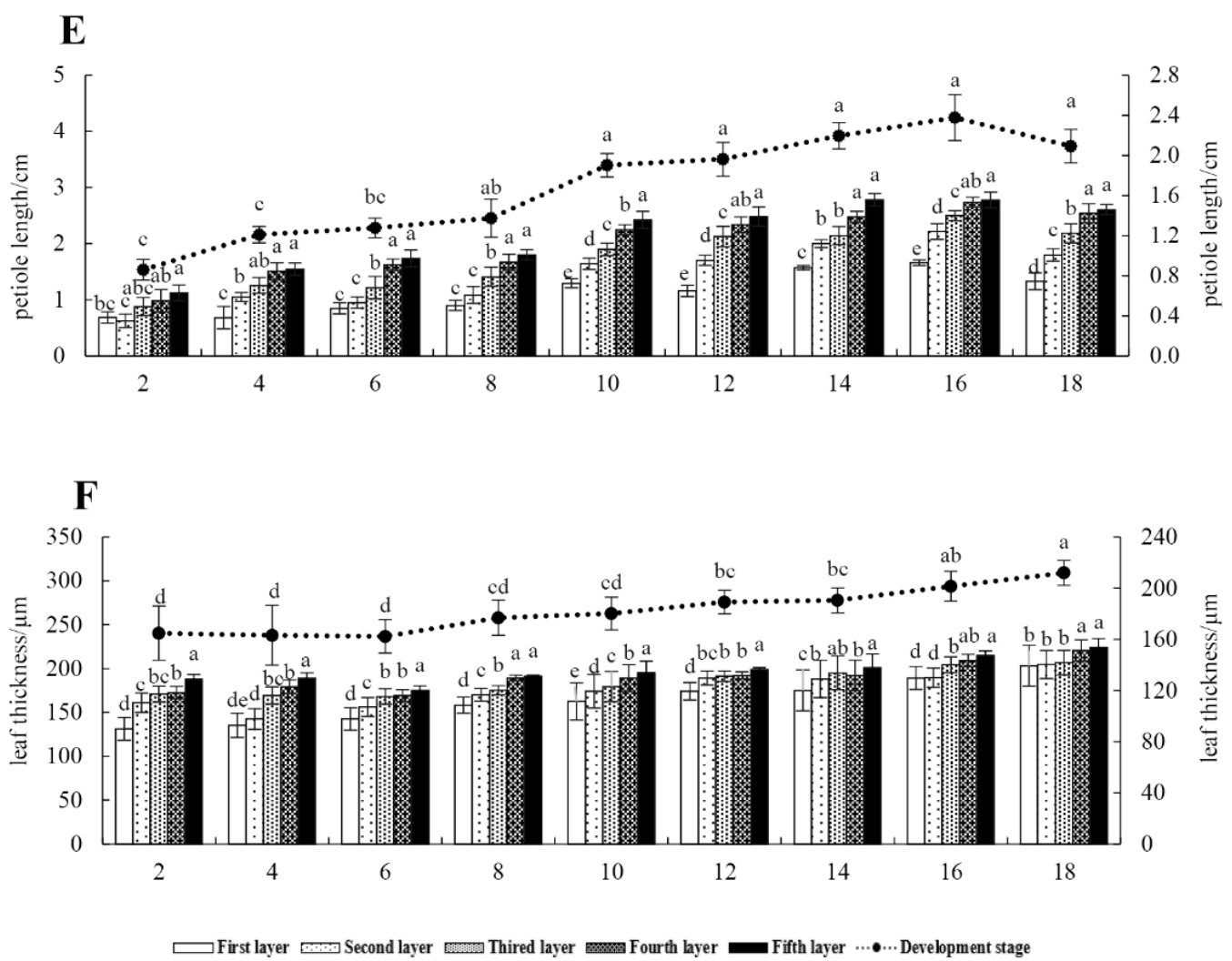

Figure 1. Variations of heteromorphic leaf morphology with developmental stage and tree height. (A) leaf length/cm,(B) leaf width/cm, (C) leaf index,(D) leaf area/ $\mathrm{cm}^{2},(E)$ petiole length/cm, $(F)$ leaf thickness/um. Lowercase letters represent significant differences, the same letters indicate that the differences are not significant, and different letters indicate significant differences. Same below

\section{Variation in anatomical structure of heteromorphic leaves with development stage and tree height}

The epidermal structure of the widest transverse section of the heteromorphic leaves in each diameter class and crown level was observed, and the results showed that the number of epidermal cells and the width of epidermal cells significantly increased with the increase of diameter class and canopy levels, and the first layer of the crown in each diameter class was significantly smaller than the fifth layer $(P<0.05)$ (Figs. 2 and $A 1)$, suggesting that the number of epidermal cells and the width of epidermal cells of $P$. euphratica heteromorphic leaves increase with increasing diameter class and canopy level.

The cell number, cell length and palisade tissue thickness in the cross section of $P$. euphratica heteromorphic leaves increased with increasing diameter class and canopy layer, and the spongy tissue thickness showed a decreasing trend. They all showed significant differences between the 2 diameter class and the 18 diameter class. $(P<0.05)$. The width of palisade tissue cells in the 12-18 diameter class increased with increasing canopy level, and the fifth layer of the canopy was significantly larger than the first layer $(P<0.05)$ (Figs. 2 and Al), indicating that the anatomical structure of heteromorphic leaves changed significantly with the increase in diameter class and canopy levels. Specifically, the palisade tissues were increasingly developed, and the sponge tissues were increasingly degenerated. 

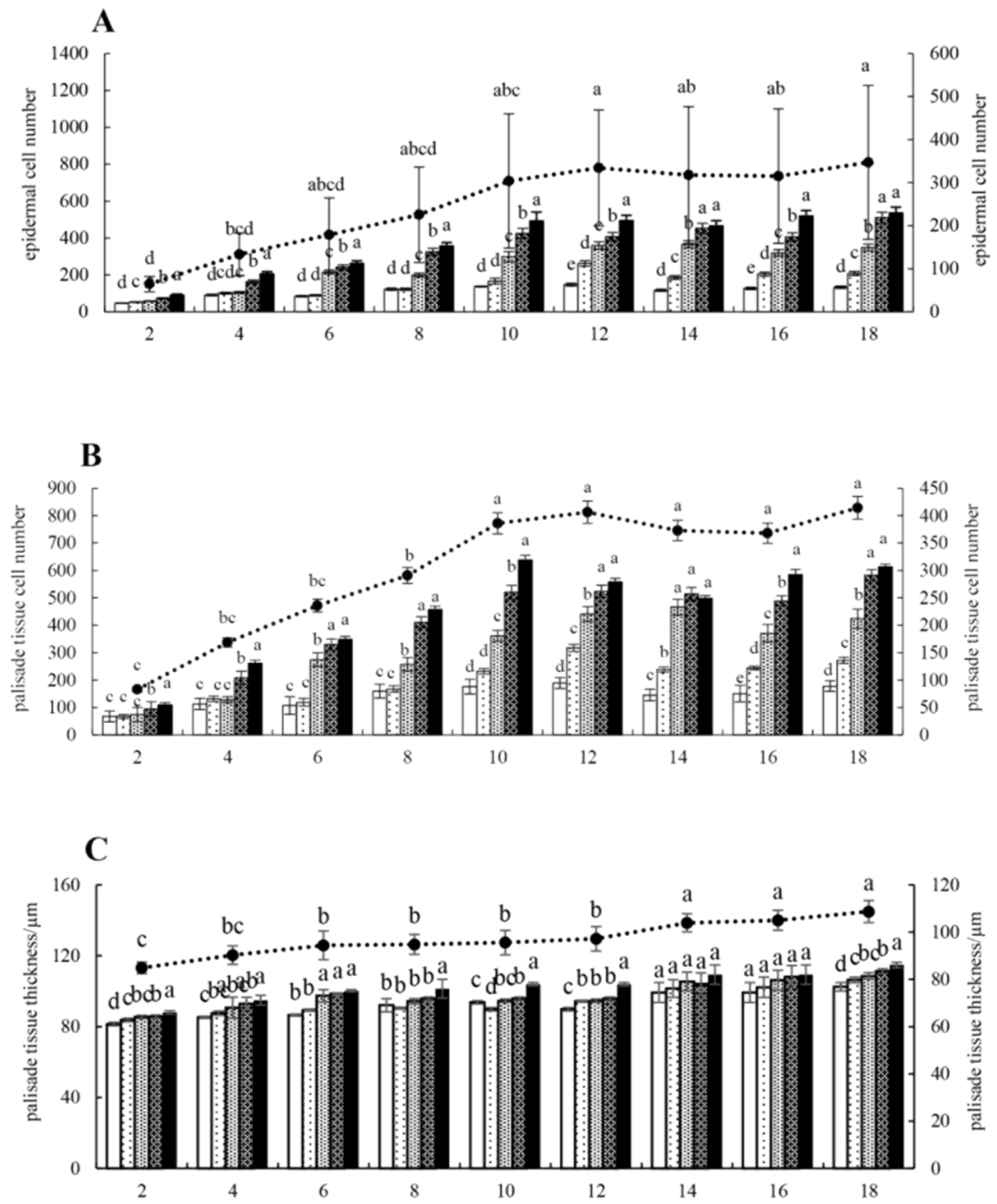

D

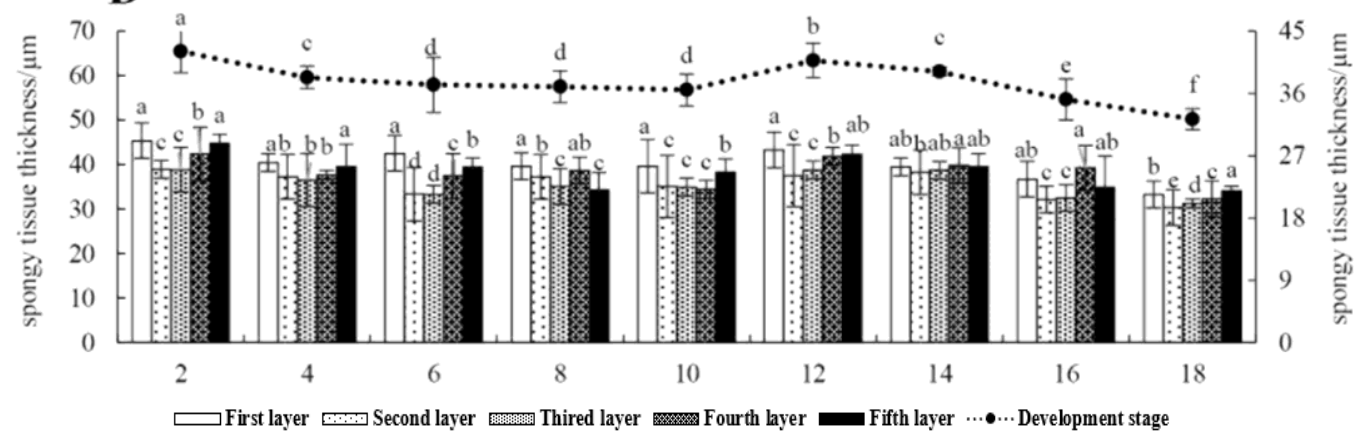

Figure 2. Variation in epidermal tissue structure of $P$. euphratica heteromorphic leaves with developmental stage and tree height. (A) epidermal cell number,(B) palisade tissue cell number, $(C)$ palisade tissue thickness $/ \mu m,(D)$ spongy tissue thickness $/ \mu m$ 


\section{Variation in endogenous hormone content and ratio of heteromorphic leaves with development stage and tree height}

Figure 3 shows, the levels of $\mathrm{GA}_{3}$ and IAA demonstrated a decreasing trend with increasing diameter class. Among them, the levels of $\mathrm{GA}_{3}$ in the fifth layer of the 2 diameter class crown were significantly higher than those in the other layers. The levels of IAA were higher in the first layer than in the fifth layer of the 10-18 diameter class. The levels of ZR increased from the 2 to 6 diameter classes. The level of ZR was not significantly different between the 2 diameter class and other diameter classes, and there was no significant difference among different levels of the crown of each diameter class. The levels of ABA gradually increased from the 2 to 6 diameter classes, with no obvious difference from the 8 to 18 diameter classes, and there were differences between the different levels of the crowns of the 10 and 14 diameter classes, indicating that the levels of 4 endogenous hormones in $P$. euphratica heteromorphic leaves showed different variations with increasing diameter class and crown level.

The hormone ratio of heteromorphic leaves was determined, and the results showed that IAA/ABA, GA $3 / \mathrm{ABA}$, and $\mathrm{ZR} / \mathrm{ABA}$ showed a decreasing trend with increasing diameter class, and IAA/ABA significantly decreased with increasing canopy levels in the 12-14 diameter class (Fig. A2). GA 3 /ABA showed an increasing trend with increasing canopy level in the 2 diameter class, while the 14 diameter class showed a decreasing trend. ZR/ABA showed an increasing trend with the increase in the canopy layer in the 10 diameter class, and the 14 diameter class showed a decreasing trend. ZR/IAA gradually increased with increasing diameter class and increased with increasing canopy layers in the 4, 6, 12 and 18 diameter classes. There was a significant difference between the fifth or fourth layer and the first layer. GA 3 /IAA showed a trend of first decreasing and then increasing with increasing diameter class, and it increased with the increase of crown level in the 2 diameter class. ZR/GA 3 increased first and then decreased with increasing diameter class, while it only showed a decreasing trend with increasing crown layer in the 2 diameter class, and there was significant difference between the fifth layer and the first layer. The results demonstrated that the hormone ratio of heteromorphic leaves also showed different variations with increasing diameter class and canopy level.

\section{Variation in carbohydrate and soluble protein of heteromorphic leaves with developmental stage and tree height}

Figure A3 shows, the contents of soluble sugar and starch decreased with increasing diameter class. Among them, the content of starch in the 10-18 diameter class increased with increasing crown layer. The first layer of the crown was significantly larger than the fourth and fifth layers. The soluble protein contents significantly decreased in the 26 diameter class, and there was no significant difference in the 8-18 diameter class, but in the 6-18 diameter class, the protein contents showed a decreasing trend with the increase in the canopy layer. The first layer of the canopy was significantly larger than the fifth layer. This suggests that the contents of soluble sugar, starch and soluble protein in heteromorphic leaves tended to be stable during the later stage of growth, and the contents of starch and soluble protein showed obvious differences in the vertical space of the crown. 


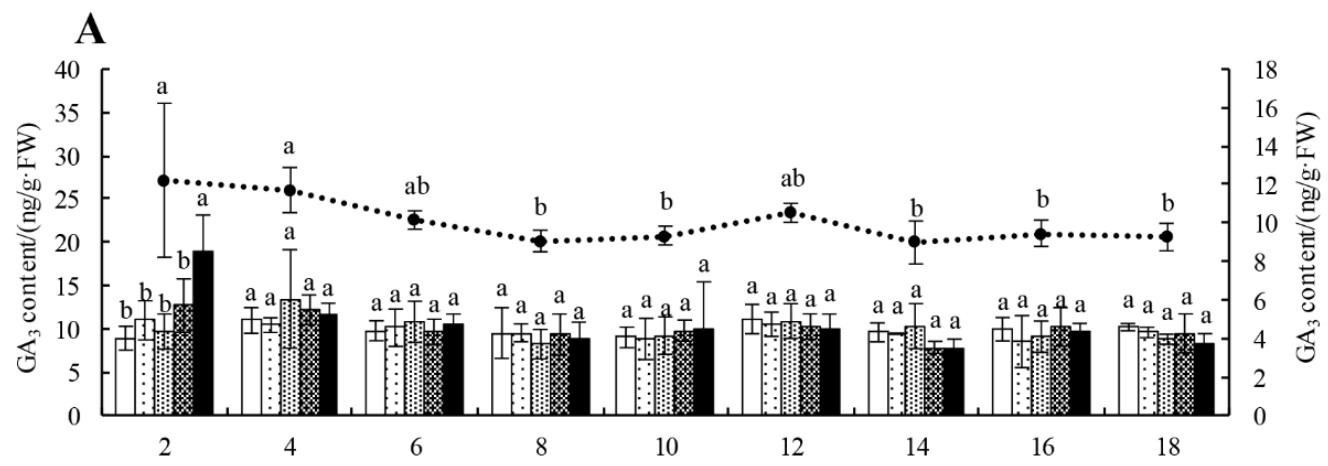

\section{B}
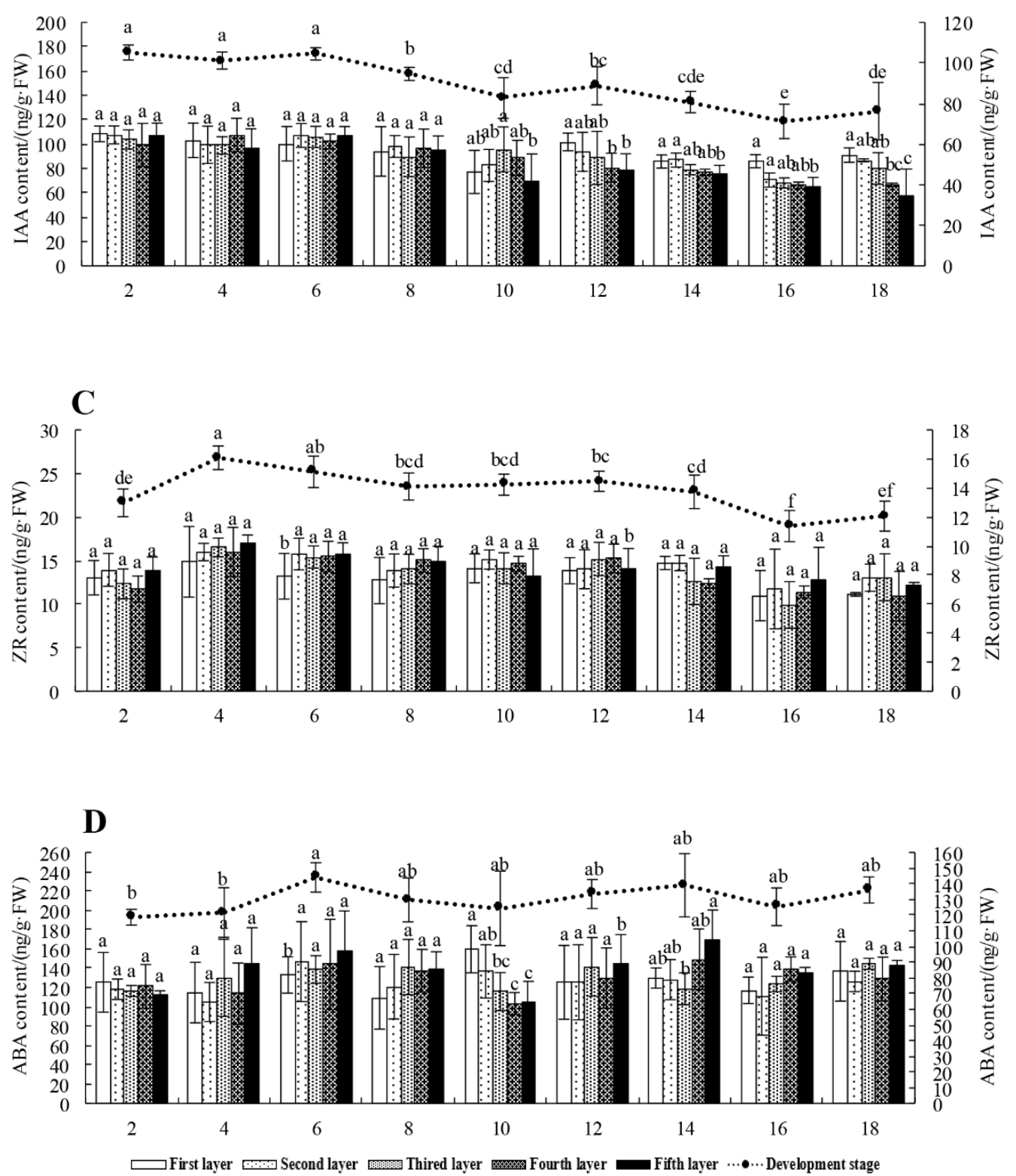

Figure 3. Variation in the endogenous hormone content of heteromorphic leaves with developmental stage and tree height. (A) GA ${ }_{3}$ content, (B) IAA content, (C) ZR content, (D) ABA content 


\section{Correlation analysis between morphological structure parameters and hormone content and ratio of heteromorphic leaves}

Correlation analysis between Morphological structure parameters and hormone contents and ratios of heteromorphic leaves was conducted (Table 1). The results showed that the IAA content, IAA/ABA, ZR/ABA and $\mathrm{GA}_{3} / \mathrm{ABA}$ were significantly negatively correlated with diameter class or crown height $(P<0.01)$. IAA content and IAA/ABA, GA $3 / \mathrm{ABA}, \mathrm{ZR} / \mathrm{ABA}$, and $\mathrm{ZR} / \mathrm{IAA}$ were significantly or extremely negatively correlated with petiole length, leaf width, leaf thickness and leaf area and were significantly or extremely positively correlated with leaf length and leaf shape index. In addition, the $\mathrm{GA}_{3}$ content was significantly positively correlated with leaf length $(P<0.01)$, and the ZR content was significantly negatively correlated with leaf width and leaf thickness and significantly positively correlated with the leaf shape index $(P<0.05)$. The ABA content of leaves was only significantly positively correlated with leaf width and leaf area $(P<0.01)$

$\mathrm{GA}_{3}, \mathrm{IAA}$ and $\mathrm{GA}_{3} / \mathrm{ABA}, \mathrm{IAA} / \mathrm{ABA}$ were significantly negatively correlated with palisade tissue cell length, palisade tissue thickness, palisade tissue cell number, and palisade tissue/sponge tissue ratio. IAA and IAA/ABA were also significantly negatively correlated with palisade tissue cell width and epidermal cell width, while $\mathrm{GA}_{3}$ and IAA/ABA were significantly positively correlated with sponge tissue thickness $(P<0.05)$ The results demonstrated that the Morphological structure parameters of heteromorphic leaves was closely related to the hormone content and ratio with increasing diameter step and crown height. The relationship between Morphological structure parameters and hormone contents and ratios of heteromorphic leaves reflects the consistency of the morphological changes and physiological changes of $P$. euphratica.

Table 1. Correlation analysis between Morphological structure parameters and hormone content and ratio of heteromorphic leaf

\begin{tabular}{|c|c|c|c|c|c|c|c|c|c|c|}
\hline & $\mathbf{G A}_{3}$ & IAA & ZR & $\mathbf{A B A}$ & IAA/ABA & $\mathbf{G A}_{3} / \mathbf{A B A}$ & ZR/ABA & $\mathbf{G A}_{3} / \mathbf{I A A}$ & ZR/IAA & ZR/GA3 \\
\hline DC & $-0.75^{*}$ & $-0.94^{* * *}$ & -0.63 & 0.4 & $-0.97^{* *}$ & $-0.73^{*}$ & $-0.77^{* * *}$ & 0.54 & $0.71^{*}$ & 0.04 \\
\hline $\mathbf{C H}$ & $-0.88^{* *}$ & $-0.88^{* *}$ & -0.47 & 0.52 & $-0.97^{* *}$ & $-0.87^{* *}$ & $-0.69^{*}$ & 0.32 & $0.76^{*}$ & 0.3 \\
\hline PL & $-0.72^{*}$ & $-0.96^{* *}$ & -0.52 & 0.31 & $-0.93^{* *}$ & $-0.68^{*}$ & -0.63 & 0.58 & $0.83^{* *}$ & 0.13 \\
\hline $\mathbf{L L}$ & $0.77^{* * *}$ & $0.87^{* *}$ & 0.42 & -0.44 & $0.92^{* *}$ & $0.76^{*}$ & $0.64^{*}$ & -0.43 & $-0.76^{*}$ & -0.22 \\
\hline $\mathbf{L W}$ & $-0.70^{*}$ & $-0.94^{* * *}$ & $-0.64^{*}$ & 0.35 & $-0.95^{* *}$ & $-0.68^{*}$ & $-0.75^{*}$ & 0.59 & $0.70^{*}$ & -0.02 \\
\hline $\mathbf{L I}$ & $0.75^{*}$ & $0.96^{* *}$ & $0.64^{*}$ & -0.36 & $0.97^{* *}$ & $0.71^{*}$ & $0.76^{*}$ & -0.57 & $-0.73^{*}$ & -0.04 \\
\hline LA: & $-0.68^{*}$ & $-0.87^{* * *}$ & -0.59 & 0.38 & $-0.90^{* *}$ & $-0.68^{*}$ & $-0.71^{*}$ & 0.52 & $0.65^{*}$ & -0.01 \\
\hline LT & -0.63 & $-0.92^{* * *}$ & $-0.74^{*}$ & 0.23 & $-0.89^{\text {** }}$ & -0.58 & $-0.77^{* *}$ & $0.64^{*}$ & 0.6 & -0.15 \\
\hline ECN & $-0.79^{* *}$ & $-0.88^{* *}$ & -0.39 & 0.43 & $-0.92^{* *}$ & $-0.77^{* *}$ & -0.56 & $0.85^{* *}$ & 0.4 & 0.29 \\
\hline ECL & -0.4 & 0.14 & -0.21 & 0.55 & -0.17 & -0.51 & -0.47 & -0.41 & -0.55 & 0.21 \\
\hline ECW & -0.45 & $-0.72^{*}$ & -0.61 & 0.29 & $-0.75^{*}$ & -0.48 & $-0.73^{*}$ & 0.43 & 0.59 & -0.23 \\
\hline PTCN & $-0.81^{* *}$ & $-0.85^{* *}$ & -0.34 & 0.45 & $-0.90^{* *}$ & $-0.79^{* *}$ & -0.52 & $0.85^{* *}$ & 0.33 & 0.36 \\
\hline PTCL & $-0.74^{*}$ & $-0.74^{*}$ & -0.34 & 0.41 & $-0.80^{* *}$ & $-0.73^{*}$ & -0.51 & $0.72^{*}$ & 0.3 & 0.26 \\
\hline PTCW & -0.58 & $-0.95^{* *}$ & -0.56 & 0.09 & $-0.83^{* *}$ & -0.48 & -0.56 & $0.79^{* *}$ & $0.70 *$ & 0 \\
\hline PTT & $-0.78^{* * *}$ & $-0.88^{* *}$ & -0.58 & 0.5 & $-0.97^{* *}$ & $-0.79^{* *}$ & $-0.79^{* *}$ & $0.65^{*}$ & 0.44 & 0.1 \\
\hline STT & $0.63^{*}$ & 0.6 & 0.41 & -0.25 & $0.63^{*}$ & 0.59 & 0.53 & -0.46 & -0.26 & -0.13 \\
\hline PSR & $-0.72^{*}$ & $-0.78^{* *}$ & -0.57 & 0.38 & $-0.84^{* *}$ & $-0.71^{*}$ & $-0.74^{*}$ & 0.54 & 0.4 & 0.05 \\
\hline
\end{tabular}

$* P<0.05, * * P<0.01$. PL: petiole length. LL: leaf length. LW: leaf width. LI: leaf index. LA: leaf area. LT: leaf thickness. DC: diameter class. CH: crown height. ECN: epidermal cell number. ECL: epidermal cell length. ECW: epidermal cell width. PTCL: palisade tissue cell length. PTCW: palisade tissue cell width. PTT: palisade tissue thickness, PTCN: palisade tissue cell number. STT: sponge tissue thickness. PSR: palisade tissue/sponge tissue ratio 


\section{Correlation analysis of morphological structure parameters and physiological and biochemical parameters of heteromorphic leaf}

Correlation analysis between the morphological structure parameters and carbohydrate and soluble protein levels of heteromorphic leaves was conducted (Table 2). The results showed that the contents of soluble sugar, starch and soluble protein were significantly or extremely negatively related to diameter at breast height, crown height, petiole length, leaf width and leaf area and significantly or extremely positively correlated with the leaf shape index. In addition, the starch content and soluble protein content were significantly or extremely positively correlated with leaf length.

The contents of soluble sugar, starch and soluble protein were significantly or extremely negatively correlated with epidermal cell number, epidermal cell length, and palisade tissue thickness. The contents of soluble sugar and starch were significantly or extremely negatively correlated with palisade tissue cell width. The starch content was significantly negatively correlated with the palisade tissue/sponge tissue ratio $(P<0.05)$. The results showed that the morphological structure of heteromorphic leaves was closely related to carbohydrate and soluble protein levels with increasing diameter steps and crown height.

Table 2. Correlation analysis between morphological structure parameters and physiological and biochemical parameters of heteromorphic leaf

\begin{tabular}{c|c|c|c}
\hline & Soluble sugar & Starch & Soluble protein \\
\hline DC & $-0.79^{* *}$ & $-0.87^{* *}$ & $-0.72^{*}$ \\
CH & $-0.81^{* *}$ & $-0.96^{* *}$ & $-0.87^{* *}$ \\
PL & $-0.88^{* *}$ & $-0.88^{* *}$ & $-0.74^{*}$ \\
LL & 0.62 & $0.82^{* *}$ & $0.75^{*}$ \\
LW & $-0.78^{* *}$ & $-0.85^{* *}$ & $-0.67^{*}$ \\
LI & $0.83^{* *}$ & $0.85^{* *}$ & $0.70^{*}$ \\
LA: & $-0.77^{* *}$ & $-0.84^{* *}$ & $-0.68^{*}$ \\
LT & $-0.75^{*}$ & $-0.76^{*}$ & -0.55 \\
ECN & $-0.93^{* *}$ & $-0.95^{* *}$ & $-0.85^{* *}$ \\
ECL & 0.19 & -0.11 & -0.26 \\
ECW & -0.33 & -0.47 & -0.37 \\
PTCN & $-0.92^{* *}$ & $-0.96^{* *}$ & $-0.87^{* *}$ \\
PTCL & $-0.65^{*}$ & $-0.82^{* *}$ & $-0.79^{* *}$ \\
PTCW & $-0.84^{* *}$ & $-0.73^{*}$ & -0.54 \\
PTT & $-0.64^{* *}$ & $-0.83^{* *}$ & $-0.72^{*}$ \\
STT & 0.26 & 0.53 & 0.54 \\
PSR & -0.46 & $-0.69^{*}$ & -0.63 \\
\hline
\end{tabular}

$* \mathrm{P}<0.05, * * \mathrm{P}<0.01$. PL: petiole length. LL: leaf length. LW: leaf width. LI: leaf index. LA: leaf area. LT: leaf thickness. DC: diameter class. $\mathrm{CH}$ : crown height. ECN: epidermal cell number. ECL: epidermal cell length. ECW: epidermal cell width. PTCL: palisade tissue cell length. PTCW: palisade tissue cell width. PTT: palisade tissue thickness, PTCN: palisade tissue cell number. STT: sponge tissue thickness. PSR: palisade tissue/sponge tissue ratio 


\section{Discussion}

\section{P. euphratica heteromorphic leaf morphological structure change and ecological adaptation}

Plants have the ability to change their shape according to environmental conditions, and this phenomenon is called phenotypic plasticity (Alpert et al., 2002; Zotz et al., 2011). Phenotypic plasticity manifests as changes in leaf morphology in response to environmental conditions, such as light intensity and quality, environmental temperature, and water utilization (Hokuto et al., 2017). Studies have shown that $P$. euphratica exhibits different leaf shapes at different developmental stages or different leaf shapes at different levels of the same plant and at different leaf nodes on the same branch, and they all demonstrate typical heteromorphic leaf characteristics related to individual developmental stages. To adapt to the arid environment, plants in desert areas try their best to change their own morphological characteristics, such as reduced leaf area or leaf degradation to assimilated branches, stomatal sinking, and leaf thickening, to resist the adverse effects of drought stress on plants. A previous study found that compared with lanceolate leaves, the xerophytic structure of broad-ovate leaves was more obvious, characterized by a thicker stratum corneum, a denser arrangement of mesophyll cells, developed palisade tissue, and more mucus cells among mesophyll cells (Yang et al., 2005). Broad-ovate leaves with a larger leaf area on the same adult plant had a more developed xerophytic structure than ovate and lanceolate leaves with a smaller leaf area (Ding et al., 2010; Li et al., 2005; Yang et al., 2005; Wang et al., 1997). The anatomical structure of heteromorphic leaves changes with increasing breast diameter at different developmental stages of $P$. euphratica (Zhao et al., 2016).

Our study showed that the morphological characteristics and anatomical structure of heteromorphic leaves changed regularly with increasing diameter class, such as larger leaf areas, longer petioles and thicker leaves. The anatomical structure of heteromorphic leaves coordinated with development in the direction of more developed palisade tissue, more degraded sponge tissue, and a larger palisade tissue/sponge tissue ratio, which was consistent with previous studies. A longer petiole is more conducive to the movement of the petiole, which receives more light to improve the photosynthetic efficiency. Thicker leaves have a better ability to store water and resist drought than thinner leaves. In addition, Levitt (Levitt et al., 1980) believed that the palisade tissue/sponge tissue ratio (PSR) was one of the important indicators to evaluate drought resistance (Zhang et al., 2017). The PSR was greater than 1 at different diameter classes, indicating that the drought resistance of $P$. euphratica was enhanced with increasing diameter class and crown height. The synergetic changes between leaf morphology and anatomical structure of heterotypic leaves not only met the energy needs of individual development, but also gradually enhanced the stress resistance of $P$. euphratica and improved the adaptability of the species to the growth environment.

\section{The role of endogenous hormones in the morphological and structural changes of heteromorphic leaves}

More recent studies have also revealed that plant hormones, including abscisic acid (ABA), gibberellin (GA), auxins (IAA) and zeatin-riboside (ZR), can affect heteromorphic leaf formation in many plant species (Hokuto et al., 2017; Li et al., 2019). For example, GA is thought to be a key factor in the regulation of heterophylly in Rorippa aquatica (Nakayama et al., 2014), and GA can reduce leaf complexity in $S$. 
lycopersicum (Yanai et al., 2011) and induce cell length growth of hydrophytes (Rijnders et al., 1997). Several studies have demonstrated that auxins affect leaf morphology and development (Barkoulas et al., 2008), regulate the cell wall structure, promote stem cell elongation, increase cell volume and affect the formation of veins and vascular tissue (Donner et al., 2009; Avsian et al., 2002). ABA can induce the formation of heterophylly in P. octandrus (Kuwabara et al., 2003). ZR can promote cell division of stems and leaves and is beneficial to the formation of leaves (Debnath et al., 2009).

Macroscopically, the morphology of the heteromorphic leaves of $P$. euphratica changed with the ontogenetic developmental stage-with the increase in tree age, heteromorphic leaves with a smaller leaf index and larger leaf area gradually appeared on the plant (Huang et al., 2010a, b; Li et al., 2017, 2015; Zhao et al., 2016). Our research shows that the 4 hormone contents and ratios of heteromorphic leaves varied with increasing diameter class and crown levels, they have different roles in the morphological and structural changes of $P$. euphratica, in terms of morphological changes of heteromorphic leaves, IAA, GA3, IAA/ABA, GA3/ABA and the ZR/ABA ratio were significantly negatively correlated with petiole length, leaf width and leaf area and positively correlated with leaf length and the leaf index. The ZR/IAA ratios showed significant positive correlations with leaf width, leaf area and petiole length and extremely significant negative correlations with leaf length and the leaf index. The contents of IAA, ZR and IAA/ABA decreased with increasing leaf thickness, and the content of ZR decreased with increasing leaf width. In terms of anatomical structure changes of heteromorphic leaves, $\mathrm{GA}_{3}, \mathrm{IAA}, \mathrm{GA}_{3} / \mathrm{ABA}$, and IAA/ABA have a significant or extremely significant negative correlation with the palisade tissue cell number, epidermal cell number, palisade tissue cell length, palisade tissue thickness and palisade tissue/sponge tissue ratio. $\mathrm{GA}_{3}$ and IAA/ABA were significantly positively correlated with sponge tissue thickness, and ZR/IAA was significantly positively correlated with epidermal cell number, palisade tissue cell number, palisade tissue cell width and palisade tissue thickness. The changes in the number of epidermal cells, palisade tissue thickness, palisade tissue cell number, palisade tissue/sponge tissue ratio and sponge tissue thickness represented the drought resistance of plants (Zhang et al., 2017; Li et al., 2017). For example, as the DBH and height gradient of the profiled leaves increase, palisade tissue thickness, sponge tissue thickness, and cuticle thickness also become thicker, indicating that the leaf anatomical structure has become more xerophyte (Zhai et al., 2019). ABA of $P$. euphratica heteromorphic leaf has long been considered a plant stress hormone and is considered a signaling molecule for drought stress in plants. ABA induction can increase a plant's ability to resist drought stress, for example, by increasing waxy deposits on the cuticle (Jana et al., 2013; Cui et al., 2016), But in our research, leaf ABA was not related to changes in the morphological structure of heteromorphic leaf, but the ratio of it to the hormones GA3, IAA, and ZR participates in the changes in the morphological structure of heteromorphic leaf. According to the analysis, the content of $\mathrm{GA}_{3}$, IAA, $\mathrm{ZR}$ and $\mathrm{ABA}$ and the ratio of IAA/ABA GA $3 / \mathrm{ABA}, \mathrm{ZR} / \mathrm{ABA}$, and ZR/IAA of $P$. euphratica heteromorphic leaf play a role in petiole length, leaf width, leaf area, leaf thickness, leaf length and the leaf index changes, $P$. euphratica regulates the drought resistance of $P$. euphratica at different developmental stages through the synergistic changes of the content and ratio of $\mathrm{GA}_{3}$, IAA, ZR and ABA in the heteromorphic leaves with the number of epidermal cells, palisade tissue thickness, sponge tissue thickness and other anatomical structures to adapt to the drought environment. 


\section{The role of soluble sugar, starch and soluble protein in the changes of morphological structure of heteromorphic leaves}

Plants under adverse stress can maintain their osmotic balance to address damage by accumulating various osmotic regulatory substances that have a regulatory role in the growth, development, maturation and senescence of plants (Shen et al., 2016). Starch, as a nutritive polysaccharide, is hydrolyzed into soluble sugar under the action of amylase. The soluble sugar content reflects the supply basis of available substances and energy in plants (Jiang et al., 2011). Studies have shown that the contents of carbohydrates and soluble proteins change regularly to adapt to environmental changes with changes in leaf morphology and ontogenetic stage (Yue, 2009). A study on the developmental process of heteromorphic leaves in $P$. euphratica found that the content of soluble sugar was always higher than that of starch, except at the initial stage of leaf development, which may be an adaptation to the arid environment (Xu et al., 2007).

Other studies on the relationship between the leaf carbohydrate and soluble protein levels and leaf morphology of $P$. euphratica at different developmental stages showed that the changes in leaf morphology were closely related to the soluble sugar and soluble protein contents ( $\mathrm{Li}$ et al., 2015). Correlation analysis results show that the contents of soluble sugar and starch in heteromorphic leaves decreased with increasing leaf width and decreasing leaf index, while the content of soluble protein decreased with decreasing leaf index and leaf length. Meanwhile, the contents of carbohydrates and soluble protein decreased with increasing palisade tissue cell number, epidermal cell number, palisade tissue cell length and palisade tissue thickness. We speculate that the metabolism of soluble sugar and soluble protein may play a regulatory role in changes in leaf length and width, as well as changes in the number of palisade tissue cells, cell length and palisade tissue thickness. In summary, $P$. euphratica regulated drought resistance during different ontogenetic stages through synergistic changes between soluble sugar and soluble protein levels and the morphological structures of heteromorphic leaves.

\section{Conclusions}

$P$. euphratica exhibited different heteromorphic leaves in different developmental stages and canopy heights. The xerophyte structural characteristics of heteromorphic leaves were obviously increased during the process. The close relationship between the 4 endogenous hormones and ratios, carbohydrate and soluble protein contents of heteromorphic leaves and the morphological characteristics and anatomical structure of heteromorphic leaves reflected the consistency of the morphological changes and physiological changes of $P$. euphratica. P. euphratica forms an ecological adaptation strategy that can cope with environmental pressure through the coordinated changes of its leaf morphology, anatomy and physiological characteristics, which provides a theoretical basis for further research on the molecular mechanism of how leaf morphology, anatomy and physiological characteristics can resist extreme environments through coordinated changes.

Acknowledgements. This work was financially supported by the National Natural Sciences Foundation of China (31860198, U1803231, 31060026), Innovative team Building Plan for key areas of Xinjiang Production and Construction Corps (2018CB003). 


\section{REFERENCES}

[1] Alpert, P., and Simms, E. L. (2002): The relative advantages of plasticity and fixity in different environments: when is it good for a plant to adjust? - Evol. Ecol 16: 285297.

[2] Avsian-Kretchmer, O. (2002): Indole acetic acid distribution coincides with vascular differentiation pattern during Arabidopsis leaf ontogeny. - Plant Physiology 1301: 199-209.

[3] Barkoulas, M., Hay, A., Kougioumoutzi, E., Tsiantis, M. (2008): A developmental framework for dissected leaf formation in the Arabidopsis relative Cardamine hirsuta. - Nature Genetics 40(9): 1136-1141.

[4] Cao, H. (2005): Botany. - China Forestry Press, Beijing, pp. 115-127.

[5] Cui, F., Brosché, M., Lehtonen, M. T., Amiryousefi, A., Xu, E., Punkkinen, M., Valkonen, J. P. T., Fuji, H., Overmyer, K. (2016): Dissecting abscisic acid signaling pathways involved in cuticle formation. - Molecular Plant 9: 926-938.

[6] Debnath, S. C. (2009): A two-step procedure for adventitious shoot regeneration on excised leaves of lowbush blueberry. - Vitro Cellular \& Developmental Biology Plant 45(2): 122-128.

[7] Ding, W., Yang, Z., Zhang, S., Chai, S. (2010): Morphological and anatomical structure of leaves on P. euphratica Oliv. in Qaidam Basin. - Journal of Desert Reseach 30.

[8] Donner, T. J., Sherr, I., Scarpella, E. (2009): Regulation of preprocambial cell state acquisition by auxin signaling in Arabidopsis leaves. - Development 136(19): 32353246.

[9] Duan, B., Li, Y., Zhang, X., Helena, K., Li, C. (2009): Water deficit affects mesophyll limitation of leaves more strongly in sun than in shade in two contrasting Picea asperata populations. - Tree Physiology 29(12): 1551-1561.

[10] He, N. P., Liu, C. C., Tian, M., Li, M. L., Yang, H., Yul, G., Guo, D. L., Smith, M. D., Yu, Q., Hou, J. H. (2018): Variation in leaf anatomical traits from tropical to cold-temperate forests and linkage to ecosystem functions. - Functional Ecology 32(1): 10-19.

[11] Hokuto, N., R., Neelima, R. S., Seisuke, K. (2017): How do plants and phytohormones accomplish heterophylly, leaf phenotypic plasticity, in response to environmental cues. - Frontiers in Plant Science 8: 1717.

[12] Huang, W., Li, Z., Yang, Z., Liang, J., Bai, G. (2010a): Heteromorphic leaf structural characteristics and their correlations with diameter at breast height of $P$. euphratica Chinese. - Journal of Ecology 29: 2347-2352.

[13] Huang, W., Li, Z., Yang, Z. P., Bai, G. (2010b): The structural traits of P. euphratica heteromorphic leaves and their correlations. - Acta Ecologica Sinica 30: 4636-4642.

[14] Jiang, C., Luo, D., Wang, L. (2011): Drought-resistant characteristics of leaf structures of five shrubs in semi-arid region of Tibet. - Journal of Northwest Forestry University 26: 13-17.

[15] Juan, C., Tingfa, D., Baoli, D., Helena, K., Ulo, N., Chunyang, L. (2015): Sexual competition and $\mathrm{N}$ supply interactively affect the dimorphism and competitiveness of opposite sexes in Populus cathayana. - Plant Cell Environ 38(7).

[16] Kalve, S., De Vos, D., Beemster, G. T. S. (2014): Leaf development: a cellular perspective. - Frontiers in Plant Science 5: 362.

[17] Koenig, D., Bayer, E., Kang, J., Kuhlemeier, C., Sinha, N. (2009): Auxin patterns Solanum lycopersicum leaf morphogenesis. - Development 136(17): 2997-3006.

[18] Kuwabara, A., Ikegami, K., Koshiba, T., Nagata, T. (2003): Effects of ethylene and abscisic acid upon heterophylly in Ludwigia arcuata (Onagraceae). - Planta 217(6): 880-887. 
[19] Leigh, A., Zwieniecki, M. A., Rockwell, F. E., Boyce, C. K., Nicotra, A. B., Holbrook, N. M. (2011): Structural and hydraulic correlates of heterophylly in Ginkgo biloba. - New Phytol 189(2): 459-470.

[20] Levitt, J. (1980): Responses of Plants to Environmental Stresses. - Academic Press, New York.

[21] Li, F., Bao, W. (2005): Responses of the morphological and anatomical structure of the plant leaf to environmental change. - Chinese Bulletin of Botany S1: 118-127.

[22] Li, Z. X., Zheng, C. X. (2005): Structural characteristics and eco-adaptability of heteromorphic leaves of P. euphratica. - Forestry Studies in China 7(1): 11-15.

[23] Li, J., Feng, M., Li, Z. (2015): Carbohydrate, soluble protein and morphometric changes of leaves of $P$. euphratica individuals under different developmental stages. - Bulletin of Botanical Research35: 43-49.

[24] Li, M. M., Liu, D., Liu, Y. B. (2016): Evaluation on drought resistant-characteristics of ten Caragana species based on leaf micromorphological structure. - Journal of Desert Research 36(3): 708-717.

[25] Li, Y., Zhang, X., Feng, M., Han, Z., Li, Z. (2017): Characteristics of endhormones in leaf blade of P. euphratica heteromorphic leaves. - Journal of Tarim University 29: 713.

[26] Li, X., He, D., Guo, Y. (2019): Morphological structure and physiological research of heterophylly in Potamogeton octandrus. - Plant Systematics and Evolution 305: 223232.

[27] Macková, J., Vašková, M., Macek, P., Hronkova, M., Schreiber, L., Santrdcek, J. (2013): Plant response to drought stress simulated by ABA application: changes in chemical composition of cuticular waxes. - Environmental and Experimental Botany 86: 70-75.

[28] Morillon, R., Chrispeels, M. J. (2001): The role of ABA and the transpiration stream in the regulation of the osmotic water permeability of leaf cells. - Proceedings of the National Academy of Sciences of the United States of America 98(24): 14138-14143.

[29] Nakayama, H., Nakayama, N., Seiki, S., Kojima, M., Sakakibara, H., Sinha, N., Kimura, S. (2014): Regulation of the KNOX-GA gene module induces heterophyllic alteration in North American Lake Cress. - Plant Cell 26(12): 4733-4748.

[30] Rijnders, J. G., Yang, Y., Kamiya, Y., Takahashi, N., Barendse, G. W., Blom, C. W., Voesenek, L. A. (1997): Ethylene enhances gibberellin levels and petiole sensitivity in flooding-tolerant Rumex palustris but not in flooding-intolerant R. acetosa. Planta 20: 20-25.

[31] Shen, H., Zhao, B., Xu, J. (2016): Relationship between leaf anatomical structure and heat resistance of 15 Rhododendron cultivars Chinese. - Journal of Applied Ecology 27: 3895-3904.

[32] Song, M., Yu, L., Jiang, Y., Lei, V., Helena, K., Ulo, N., Li, C. (2017): Nitrogencontrolled intra- and interspecific competition between Populus purdomii and Salix rehderiana drive primary succession in the Gongga Mountain glacier retreat area. Tree Physiology 37(6): 1.

[33] Wang, H., Yang, S., Zhang, C. (1997): The photosynthetic characteristics of differently shaped leaves in P. euphratica Olivier. - Photosynthetica 34(4): 545-553.

[34] Wright, I. J., Dong, N., Maire, V., Prentice, I. C., Westoby, M., Díaz, S., Gallagher, R. V., Jacobs, B. F., Kooyman, R., Law, E. A., Leishman, M. R., Niinemets, Ü., Reich, P. B., Sack L., Villar, R., Wang, H., Wilf, P. (2017): Global climatic drivers of leaf size. - Science 357(6754): 917-921.

[35] Xu, S., Feng, J. C., Jiang, L., Zhang, C. (2007): Variation of saccharides in young leaves of P. euphratica in E Jina County. - Journal of The Central University for Nationalities (Natural Sciences Edition) 16: 210-216.

[36] Xu, Y., Pu, W., Yu, Z., Yang, Y., Ma, H. (2018): Differences in leaf anatomical structure of different life-form plants in the same community in the dry-hot valley of 
the Jinsha River. - Journal of Southwest Forestry University (Natural Science) 38(06): 74-82.

[37] Yanai, O., Shani, E., Russ, D., Ori, N. (2011): Gibberellin partly mediates LANCEOLATE activity in tomato. - Plant Journal 68(4): 571-582.

[38] Yang, S., Zheng, W., Chen, G., Zhang, C., Chen, J., Wang, X. (2005): Difference of ultrastructure and photosynthetic characteristics between lanceolate and broad-ovate leaves in P. euphratica. - Acta Botanica Boreali-Occidentalia Sinica 25: 14-21.

[39] Yang, J. H., Li, Y. A., Bu, H. Y., Zhang, S. T., Qi, W. (2019a): Leaf traits of common broad-leaved woody plants on the eastern edge of the Qinghai-Tibet Plateau respond to environmental factors. - Acta Plant Ecology 43(10): 863-876.

[40] Yang, J., Li, Y., Bu, H., Zhang, S., Qi, Wei. (2019b): Responses of leaf traits of common broad-leaved woody plants on the eastern edge of the Qinghai-Tibet Plateau to environmental factors. - Acta Plant Ecology 43(10): 863-876.

[41] Yue, N. (2009): Anatomical and Physiological Characteristics of Eco-adaptability of Heteromorphic Leaves in P. euphratica Oliv. - Beijing Forest University, Beijing.

[42] Zhai, J., Li, Y., Han, Z., Li, Z. (2020): Morphological, structural and physiological differences in heteromorphic leaves of Euphrates poplar during development stages and at crown scales. - Plant Biology. https://doi.org/10.1111/plb.13078.

[43] Zhang, J., Li, Y., Pang, M., Zhu, C., Bi, Z. (2017): Comparison of drought resistance of anatomical structure in the heterophylly mechanism of Sabina vulgaris. - Acta Botanica Boreali-Occidentalia Sinica 37: 1756-1763.

[44] Zhao, P., Feng, M., Jiao, P., Li, Z. (2016): Morphological and anatomical characteristics of leaves of $\mathrm{P}$. euphratica at different developmental stages and their relationship with diameter at breast height. - Arid Zone Research 33: 1071-1080.

[45] Zhou, L., Xu, H., Mischke, S., Meinhardt, L. W., Zhang, D., Zhu, X., Li, X., Fang, W. (2014): Exogenous abscisic acid significantly affects proteome in tea plant (Camellia sinensis) exposed to drought stress. - Horticulture Research 1: 14029.

[46] Zotz, G., Wilhelm, K., Becker, A. (2011): Heteroblasty-a review. - Bot. Rev 77: 109-151. 

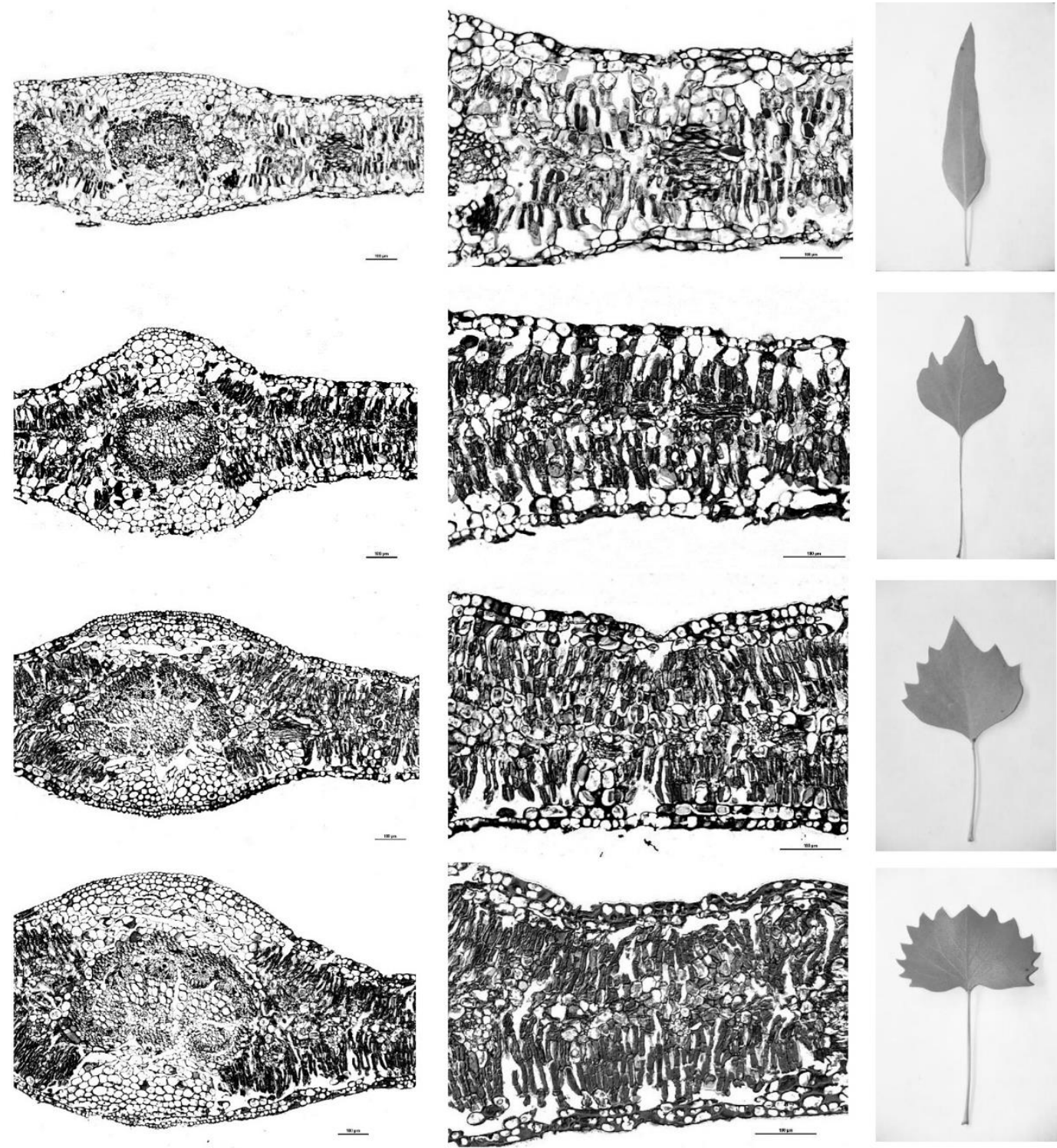

Plate 1. Anatomical structure and epidermal stomata of Populus euphratica in strip, lanceolate, ovate, broad ovate leaves. From top to bottom are the first to fifth layers of the crown of Populus euphratica heteromorphic leaf D stage, corresponding to the anatomical structures of striped leaves, lanceolate leaves, ovate leaves, and broad-ovate leaves; The magnification and leaf shape photos are respectively $10 X 10$ times, 10X20 times, and leaf shape photos 

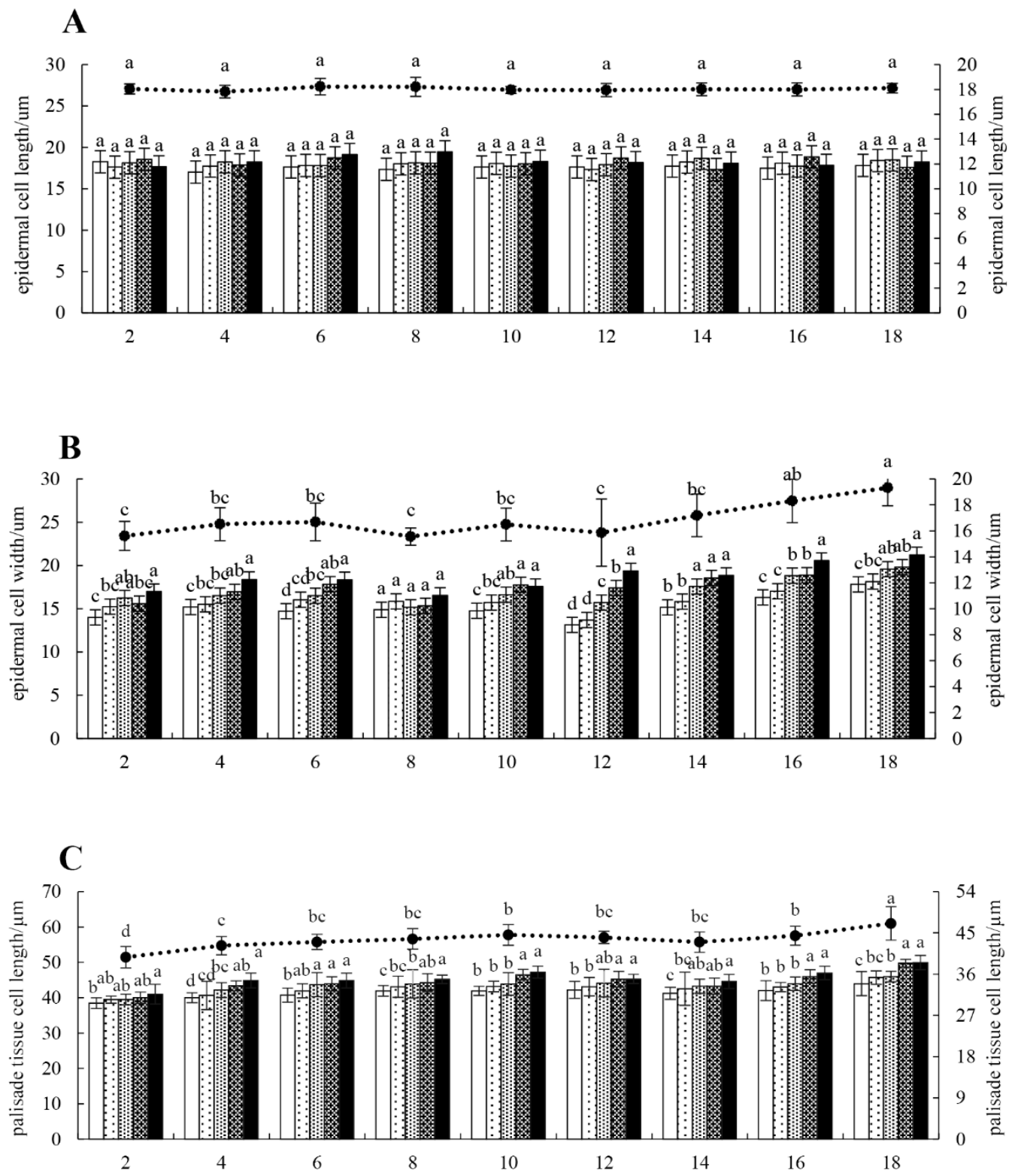

D

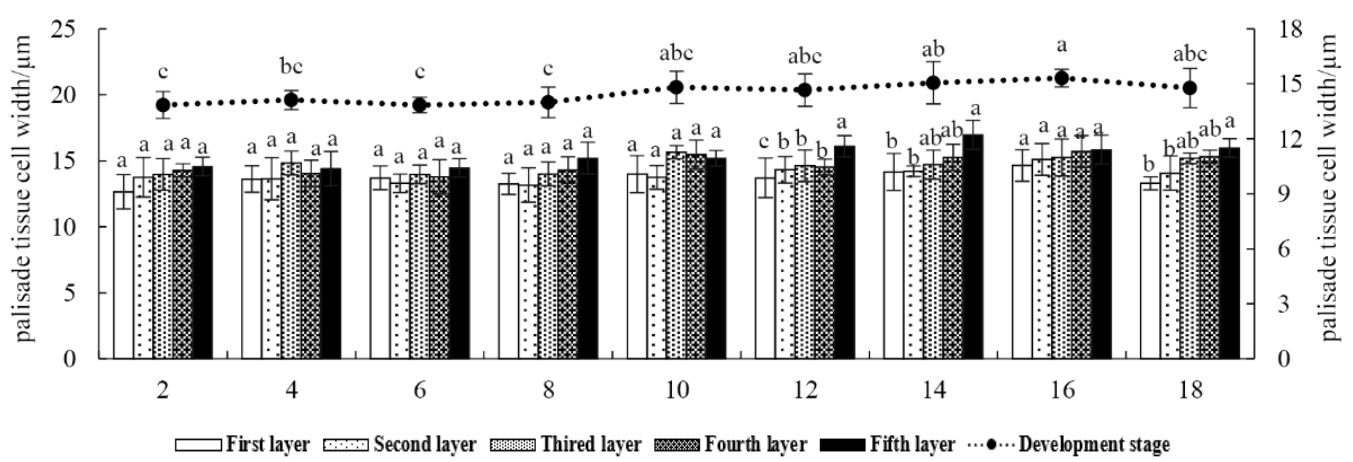

Figure A1. Variation in heteromorphic leaf anatomical structure with development stage and

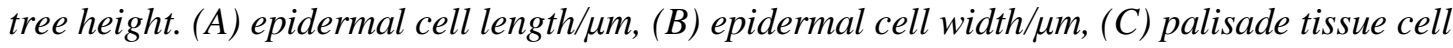

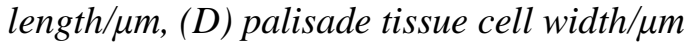




$$
\text { - } 2278 \text { - }
$$
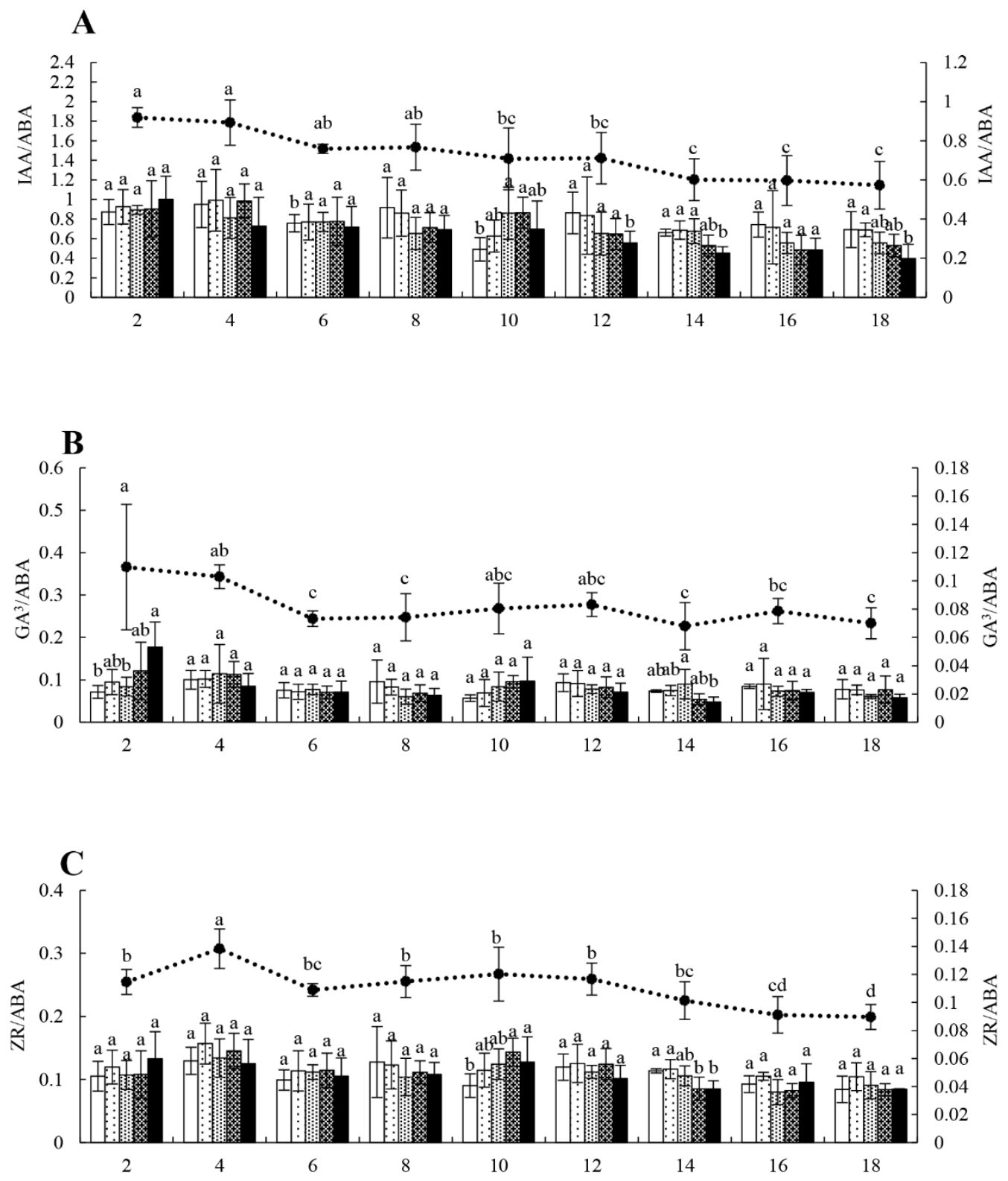

D

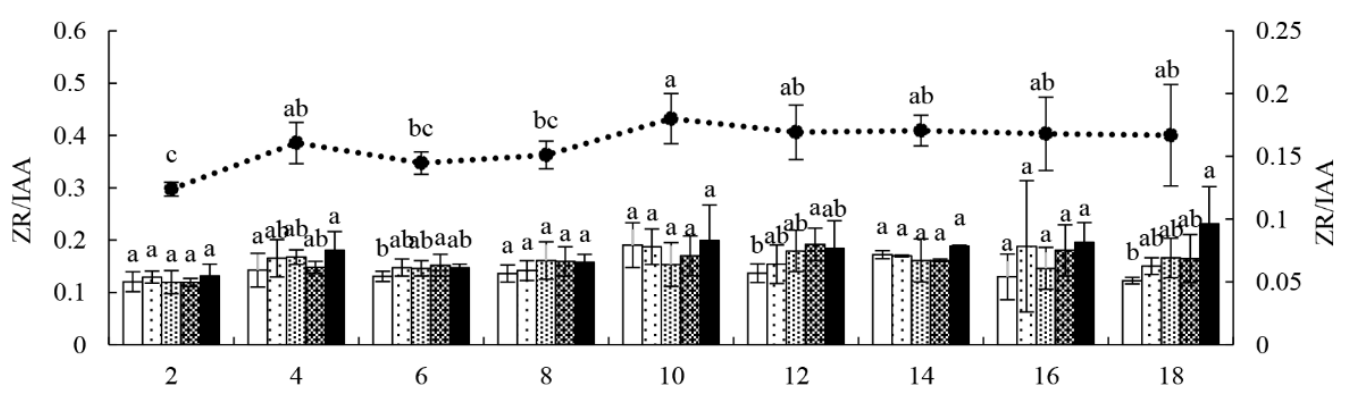




$$
\text { - } 2279 \text { - }
$$
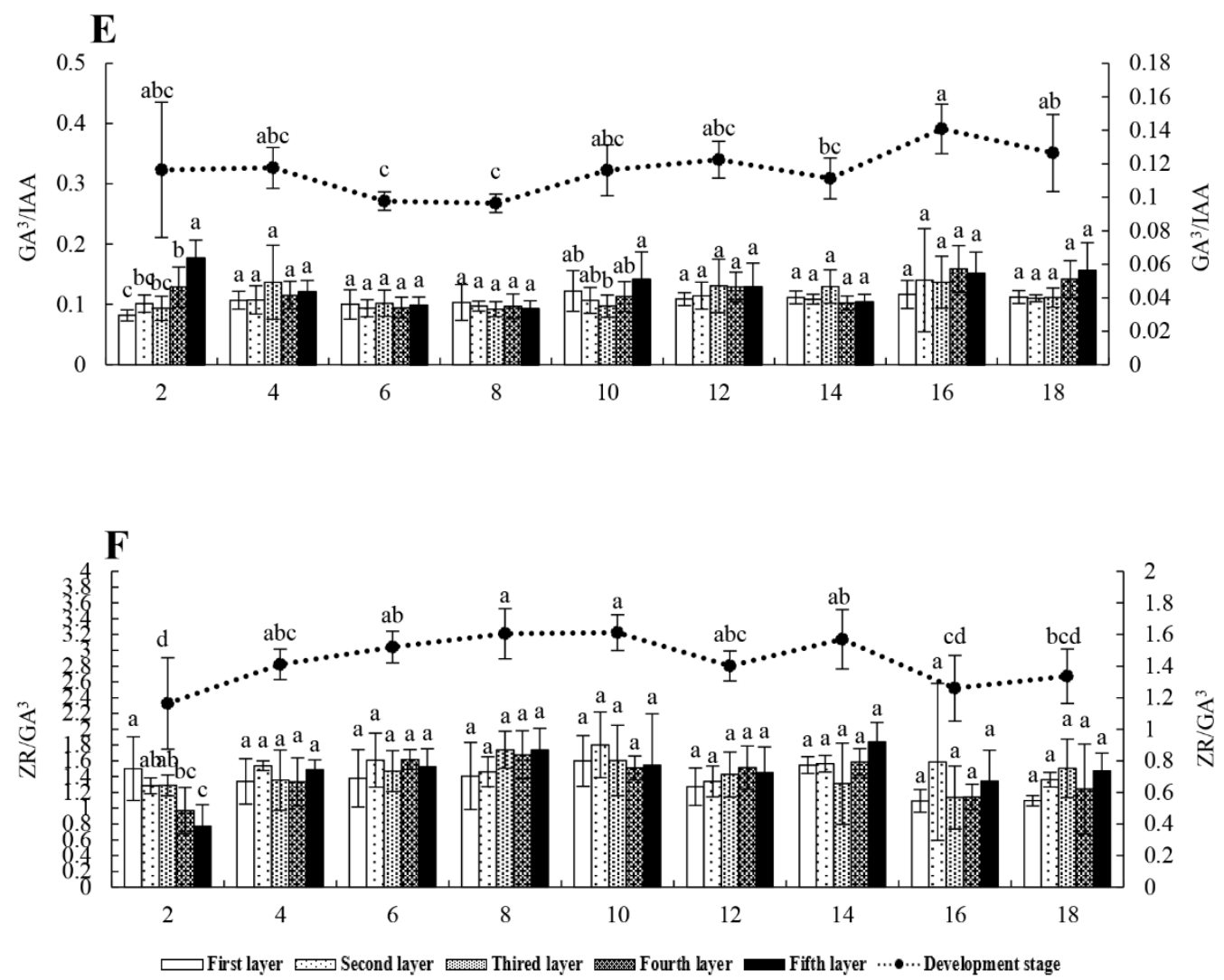

Figure A2. Variation in the endogenous hormone content ratio of heteromorphic leaves with developmental stage and tree height. (A) IAA/ABA, (B) GA $3 / A B A$, (C) ZR/ABA, (D) ZR/IAA (E) $G A_{3} / I A A,(F) Z R / G A_{3}$ 

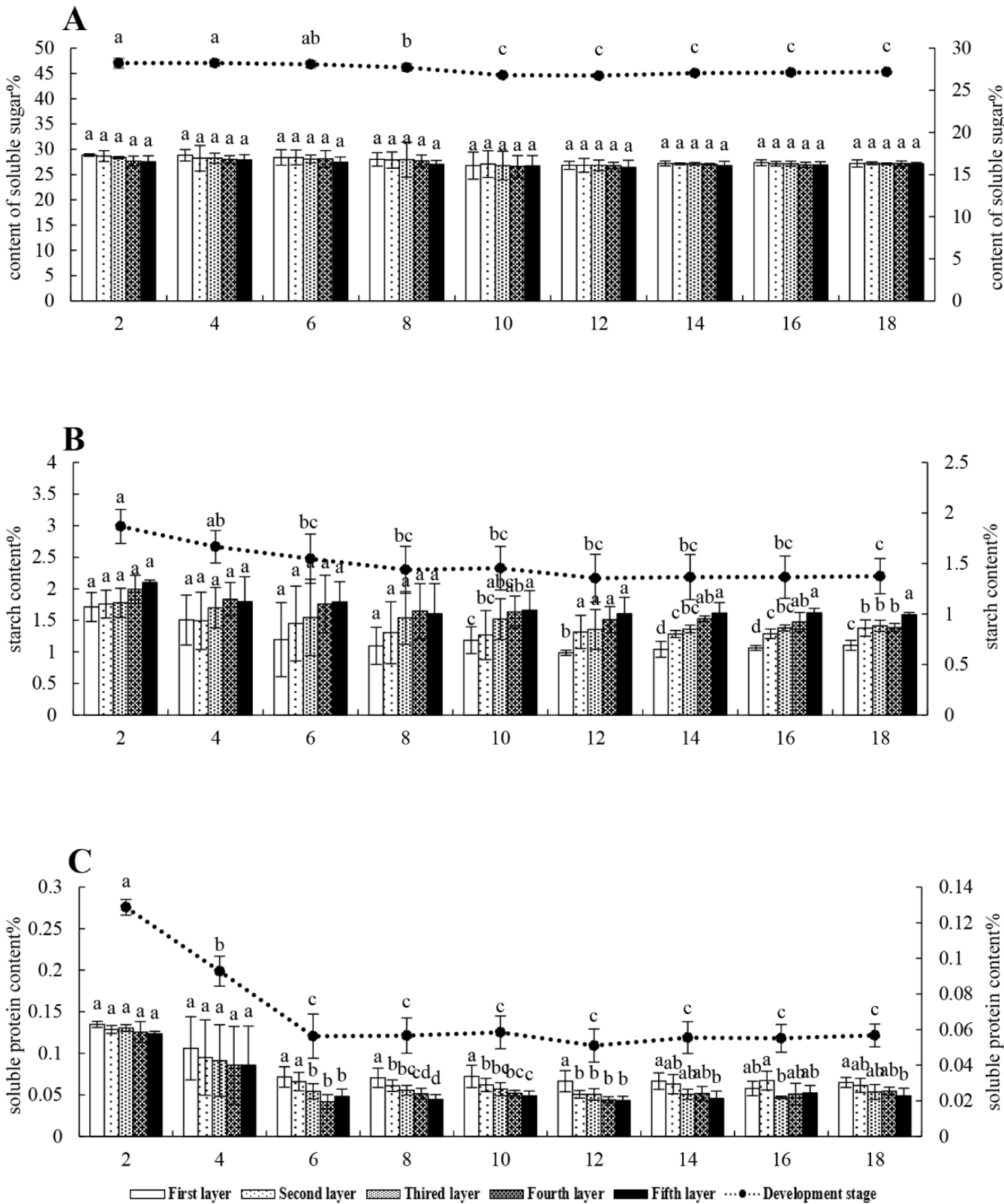

Figure A3. Variation in the carbohydrate and soluble protein of heteromorphic leaves with developmental stage and tree height. (A) content of soluble sugar\%, (B) starch content\%, (C) soluble protein content $\%$

Table A1. Basic information of P. euphratica

\begin{tabular}{c|c|c|c|c|c|c|c|c|c}
\hline Diameter classes & $\mathbf{2}$ & $\mathbf{4}$ & $\mathbf{6}$ & $\mathbf{8}$ & $\mathbf{1 0}$ & $\mathbf{1 2}$ & $\mathbf{1 4}$ & $\mathbf{1 6}$ & $\mathbf{1 8}$ \\
\hline Breast diameter range & $0-2 \mathrm{~cm}$ & $2-4 \mathrm{~cm}$ & $4-6 \mathrm{~cm}$ & $6-8 \mathrm{~cm}$ & $8-10 \mathrm{~cm}$ & $10-12 \mathrm{~cm}$ & $12-14 \mathrm{~cm}$ & $14-16 \mathrm{~cm}$ & $16-18 \mathrm{~cm}$ \\
Number of plants & 20 & 78 & 67 & 59 & 48 & 43 & 29 & 8 & 3 \\
Mean breast diameter (cm) & 2.3 & 3.9 & 5.9 & 7.9 & 9.8 & 12 & 14.1 & 15.7 & 17.4 \\
Average tree height (m) & 6.3 & 8.8 & 8 & 8.1 & 8.7 & 9.7 & 10 & 9.6 & 11.1 \\
Average crown height (m) & 2.4 & 3.9 & 5.7 & 6.8 & 7.2 & 7.5 & 8.4 & 8.6 & 9.4 \\
Average tree age (year) & 4.1 & 5.2 & 6.6 & 7.6 & 8.6 & 10.3 & 10.5 & 11.3 & 11.6 \\
Number of samples (pcs) & 9 & 31 & 23 & 21 & 20 & 19 & 11 & 4 & 3 \\
\hline
\end{tabular}

